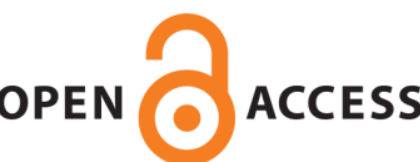

OPEN ACCESS

UWS Academic Portal

\title{
Research network on regional economic and policy history
}

Van Der Zwet, Arno; Molema, Marijn

Published in:

Planning Perspectives

DOI:

10.1080/02665433.2017.1331753

E-pub ahead of print: 06/06/2017

Document Version

Peer reviewed version

Link to publication on the UWS Academic Portal

Citation for published version (APA):

Van Der Zwet, A., \& Molema, M. (2017). Research network on regional economic and policy history. Planning Perspectives, 32(3), 459-466. https://doi.org/10.1080/02665433.2017.1331753

\section{General rights}

Copyright and moral rights for the publications made accessible in the UWS Academic Portal are retained by the authors and/or other copyright owners and it is a condition of accessing publications that users recognise and abide by the legal requirements associated with these rights.

\section{Take down policy}

If you believe that this document breaches copyright please contact pure@uws.ac.uk providing details, and we will remove access to the work immediately and investigate your claim. 


\section{Research Network on Regional Economic and Policy History}

\section{Marijn Molema}

Fryske Akademy/Royal Dutch Academy of Sciences, Leeuwarden, the Netherlands Department, University, City, Country

Doelestraat 8, 8911 DX Leeuwarden, the Netherlands. Email address:

m.molema@ fryske-akademy.nl

Marijn Molema specializes in nineteenth and twentieth-century history at the Fryske Akademy (FA), a research institute in Leeuwarden which is part of the Royal Netherlands Academy of Arts and Sciences (KNAW). His research focuses on regional-economic development from the Industrial Revolution onwards, with special emphasis on policies and agribusiness clusters.

\section{Arno van der Zwet}

School of Media, Culture and Society, University of the West of Scotland, Paisley, United Kingdom

East Elles Building, High Street, PA1 2BE Paisley, United Kingdom. Email address: Arno.van-der-van-der-zwet@uws.ac.uk

Arno van der Zwet specializes in European territorial development at the University of the West of Scotland in Paisley. He also an Senior Research Associate at the European Policies Research Centre at the University of Strathclyde in Glasgow. His research interests include regional economic development policy, territorial cooperation and urban development. 


\section{Research Network on Regional Economic and Policy History}

In the spring of 2017, the Research Network on Regional Economic and Policy History organised its inaugural workshop in London. The network aims to stimulate research in relation to regional economic development and planning challenges, by exploring the importance of historical approaches and methodologies whilst uncovering linkages between historical science and regional studies. The added value of historical perspective is that it assists to reveals path dependencies in a region's economy and can provide learnings in terms of the successes and failures of policy instruments, strategies and institutions that are responsible for the implementation of regional policy. Furthermore, history can provide much needed 'thick' descriptions which highlight contingencies. This contribution first explores the perspectives for interdisciplinary exchange between the study of history and the fields of regional and planning studies. Subsequently, it provides an outline of the aims and objective, key activities and participants of the network.

Keywords: historical perspectives; regional policy; methodology; interdisciplinarity; endogenous growth theory

\section{Introduction}

The past plays a crucial role in understanding, developing and implementing regional economic planning and development policies. History reveals path dependencies in regional economies and can help to identify the successes and failures of policy instruments. This basic idea lies at the core of the Research Network on Regional Economic and Policy History (ReHi). The network has been awarded a grant, as part of its 50th anniversary, from the Regional Studies Association in October 2016. In our view, as initiators, the aim of the network is to explore, what a historic perspective may contribute to regional (planning) studies as well as current regional policy making and how approaches and methodologies used by historians can be better integrated in the 
regional (planning) studies. The network offers a meeting place for scholars from a broad variety of disciplines with an interest in regional development and planning issues from a historical perspective.

Two sections of this paper set out the context and background of the network, focussing on the limited integration of historical methodologies in the regional studies. The concluding sections embarks on the aims and objective, key activities and participants of the network. If this article has piqued your interest we cordially invite you to get in touch with us and to become involved in the network at an early stage.

\section{Context and background}

Regional studies has a long tradition of using historical approaches to explain regional development challenges and policies. Scholars, planners, politicians, policy makers and other stakeholders with an interest in regional studies are acutely aware of the importance of a historic perspective to deal with modern day regional economic development challenges. Academic contributions to debates on cluster development illustrates that historical awareness within regional (planning) studies is growing. For example, economic geographers stress the 'non-linear dynamics' and 'path-dependency' of clusters, and underline the necessity of understanding singular historical processes within the development of clusters. ${ }^{1}$

From such a perspective, the step towards the field of (economic) history is very small. At the same time there is still a lack of exchange between both domains of the social sciences - notwithstanding some exeptions. ${ }^{2}$ Historical contributions on economic history and planning are hardly noticed within regional studies. ${ }^{3}$ Conversely, important contributions to the regional (planning) studies literature on evolutionary development and institutional change are regularly overlooked by historians. ${ }^{4}$ Both 
disciplines have their own channels and conventions of academic publishing, which hampers intellectual exchange.

Academic engagement in the process of regional economic planning is mostly restricted to the interdisciplinary group of geographers, planners, political scientists and economists. As a consequence, in-depth and analytical reflections on the past are only occasionally part of the policy process, despite the contribution of historical perspectives to strategic reasoning for future development. Therefore we should make the added value of history more explicit, and explore the similarities and potential synergies between history and regional studies.

One added value of a applying a historical approach is that it helps to grasp continuities and changes within regional economies and its accompanying policies, which helps us to assess the impact of policy measures that have been implemented. The need for long term historical analyses has become more pertinent in the last two or three decades, compared to the post-war period. In the 1950s and 1960s, a strong consensus among the key stakeholders of regional policies existed, and the ambitions for state-led development were not hindered by economic downturns, as was the case in the last quarter of the twentieth century. Regional industrial policies did not distinguish between places: all places and territories had to be developed, more or less, according to the same basic set of instruments, such as premium subsidies for industrial companies, building roads and harbours, and the construction of industrial parks. These instruments intended to reduce the regional backwardness compared to national averages of economic development.

Critical opposition to this paradigm emerged in the second half of the $1970 \mathrm{~s} .{ }^{5}$ In the last two decades of the twentieth century, countless contributions to regional development theories stressed the importance of the special characteristics of a territory, 
offering an alternative to the homogenous policies of the post war period. Slowly but surely, a new set of development ideas arose which filled up the analytical void once the industrial development paradigm was dropped. In the new paradigm, growth determinants were located inside, instead of outside the region and gave birth to concepts such as 'endogenous' regional development and more recently examples of place-based approaches. ${ }^{6}$

Looking back on forty years of experience with endogenous growth policies, however, we can discern some tensions. One of them is the proliferation of interpretative frameworks that aim to help regions to recognise and acknowledge their economic potentials. New concepts such as economic clusters, learning regions and regional innovation systems have been launched in quick succession. ${ }^{7}$ Some of the new concepts are rhetorically overwhelming and are difficult to translate into policy programmes that really stimulate regional development, especially in vulnerable regions. A concept like 'learning region' has therefore been criticised for being just another fancy term used by consultants rather than being grounded in evidence-based scholarship. Moreover, many of the ideas developed within the framework of endogenous growth policies are deeper rooted into academic traditions (and therefore the policy implications are already existent) than most proponents of these concepts suggest. ${ }^{8}$

\section{Methodological challenges}

Against this background, well known representatives from regional studies have urged for more conceptual coherence, and the 'subjection of theory to the rigours of evidence'. ${ }^{9}$ This call for more theoretical and analytical rigour chimes with our stated need for a more sustained use of historical methodologies in the discipline of regional 
studies and an integration of these methodologies in the regional studies. A focus on the longue durée captures the regions' development, the role of policies and can contribute to an objectified body of knowledge about the economic qualities and influence of economic politics and policies within particular regions. This is not to say that historical perspectives have been obsolete in regional studies. Concepts as path-dependency, institutional and evolutionary development play an important role here. ${ }^{10}$

However, these concepts are most of the time operationalised differently when compared to historical research projects. Evolutionary and institutionalist economics start from a distinct methodological basis with clear models and theoretical frames guiding the research questions. Such an approach is not absent in historical studies, but on many occasions this field of research applies a more inductive approach to research. Lots of regional studies scholarship that pays attention to longer term developments lacks, in the eyes of inductive historians, refined and empirical analysis of the historical process. Exceptions on this general feeling is regional studies research which applies quantitative and/or qualitative analysis of processes and events, as well as the role of individual and collective actors within these historical developments. ${ }^{11}$ Such studies reveal continuities and changes of regional development over the long term, and provide a helpful basis for interdisciplinary connections between history and regional studies.

Besides a more thorough understanding of longer term developments, another added value of history is that it is able grasp contingency: the more or less coincidental circumstances which drive regional processes and developments. As the business historians Popp \& Wilson have stated, the 'narrative skills and instincts' of historians make them well equipped for the analysis of contingent factors affecting regional economies and policies. ${ }^{12}$ For many scholars within the field of regional studies, the use of conceptual models is a conventional unproblematic approach to conducting research. 
For them, good science is imbedded in clear theories and hypothesis, and steers the collection of empirical data during the research process. However, this a-priori approach may hinder a more holistic understanding of development and the role of contingency in these processes. In short, contingency means that regional development and economic policies are dependent on their context and are influenced by unforeseen circumstances as well as unintended consequences. In order to grasp these contexts and different circumstances, we should have an open mind to research in which case an inductive approach may be more suitable. This is not to say that only historical sciences can do justice to contingent factors, but they are well equipped to trace contextual aspects and relate them to regional policies and economic development.

Historians also face some challenges. The methods that economic historians have to their disposal have much in common with mainstream approaches in regional studies. Many historians, however, are unable to communicate their methodology as a chronological set of steps that have been taken in order to reach their conclusion. Instead, their way of understanding regional issues can be explicated with the help of philosophical hermeneutics, which is a body of knowledge within the philosophy of science led by Gadamer. ${ }^{13}$ Starting with an actual issue in the present (like 'regional development') one tries to reconstruct and understand processes in the past. Narratives resulting from this historical inquiry are subjective, in the sense that they are coloured by the interpretations of the researcher (and events in the future). This is not a major problem, as long as the historical narrative connects to current issues and helps for a better understanding of ongoing problems.

Historiographical literature offers all kind of examples that have implications for regional economies and policies and demonstrate the linkages between historical science and regional studies. There are historians who have analysed, using quantitative 
as well as qualitative approaches, how dynamic processes of economic growth were regional concentrated across Europe. Economic historians have put much effort in (sometimes: thick) descriptions which helps us to understand regional dynamics since the Industrial Revolution. ${ }^{14}$ The history of policies is a subdomain within the historical sciences, which helps to reflect on regional policies in the long term. An overview of Doering-Manteuffel sketches the continuity and change of politicized discourses in the twentieth century, which steered the order of society into the direction of (changing) preferences. ${ }^{15}$ Insight in such macro-ideologies helps to understand how the notion of 'regional development' was modified, and connects to geographers who plead for the historical contextualization of the term 'development'. ${ }^{16}$ A recent contribution in the Journal of European History underlines the importance of a decentralized approach of understanding planning processes. ${ }^{17}$ Such an approach could help us to understand contingent factors and regional differences in regional economic policies. Finally, we should point at the sub discipline of planning history in which development strategies of the past are studied. The International Planning History Society facilitates historical reflection on spatial and economic development. IPHS-conferences and the Planning Perspectives journal gives inspiration to stimulate a more explicit focus on the history of economic planning in regions.

\section{Aims and objective of the network}

The background section has outlined the gaps between regional studies and historical scholarship as well as identified some of the linkages between the two. The main objective of the network is to explore, what a historic perspective may contribute to regional studies as well as current regional policy making and how approaches and methodologies used by historians can be better integrated in the regional studies. As 
such the network reflects on the methodologies and historiographies of both the historical sciences and regional studies. The network will examine processes of continuity and turning points in regional development and policy making; identifying those events in history that provide opportunity for advancement, or in some cases, regression. It offers an opportunity to analyse regional development in the context of larger trends and processes such as state expansion and retraction, including austerity, economic crisis, European integration, EU enlargement and neighbourhood involvement, administrative professionalization, new public management, etc.

Furthermore, it will specifically reflect on the outcomes and results of regional policy over the longue durée.It also explores the ways in which regional development is conceptualised in different time periods and identifies typologies which can advance our understanding of regional policy development and its impact in different geographies over time. Those who are connected to the network so far are mainly based in Europe and the UK, but there is no geographical limitation and the network organisers hope to involve scholars from other continents as well. Fundamentally, the network brings together researchers from different fields, such as Regional Studies, economic history and planning history. In workshops and joint publications, academics from various scientific backgrounds explore together in which ways they can complement each other. It will look to identify approaches and collaboration that are of added value to both the study and the practice of regional development

\section{Key activities}

In order to achieve the above stated aims the network will organise five 'stand-alone' international workshops at different locations in Europe. The workshops aim to encourage open discussion, learning and fostering collaboration between academics and 
policy makers. Each of the workshops are locally organised. The inaugural workshop has explored interdisciplinary connections between regional studies and history. In the second workshop issues in relation to cross border and transnational regions will be the focus, and explore the long term economic and policy development within these regions. The third workshop deepens the interdisciplinary discussion by questioning the historical construction of regions and regionalism. The last two network workshops are coupled to a specific concept respective urban space: an historical account of resilience in regional economic systems (4th workshop) and the economic and policy history of urban spaces (5th workshop). Next to the five network workshops, two special sessions will be organised during a RSA European Conference. The first special event will focus on the history of regional policies in different countries, while the last special event is a round table in which ideas about a follow up research agenda will be discussed.

(1) Inaugural meeting (UCL, London/England): 25-26 April 2017

(2) Cross border regions (Central European University, Budapest/Hungary): 29-30 June 2017

(3) Regional constructions (Centre of regional Studies, Karlstad/Sweden): 30-31 October 2017

(4) Resilience in history (Fryske Akademy, Leeuwarden/the Netherlands): January 2018

(5) Urban policies (Uni. Of West-Scotland, Paisley/Glasgow/Scotland): Oct/Nov 2018

\section{Participants}

The network invites scholars and students from a broad range of disciplines. We especially (but not exclusively) invite: 
- Economic geographers, human geographers, political scientists economists and sociologists who include historical perspectives in their work

- Planning historians, economic historians, political historians, urban historians

We also invite early career researchers and $\mathrm{PhD}$ students to become involved in the network as well as policymakers and civil society actors that have an interest in a historical perspective on regional economic development policy.

\section{Invitation}

The network aims to develop a long term, multi-disciplinary collaboration for future projects, publications and policy engagement activities. We will be publishing Calls for Papers for each of the workshops in due course. We hereby invite you to contribute to the early stages of this endeavour which provides opportunities to shape thinking and future research activities. If you wish to be added to the mailing list in order to receive information regarding the workshops and other project events please contact us. We would also invite you to get in touch with any personal experiences you may have in terms of the themes for the network. For all these matters, you can e-mail the key contact name of the network, Marijn Molema, via the mailadress m.molema@fryskeakademy.nl 


\section{Notes}

1. Martin and Sunley, “Conceptualizing cluster evolution”, 1303-1304.

2. Hudson, Wrecking a region, 433p.; Popp and Wilson, "Life cycles", 2975-2992.

3. f.e. Leendertz, Ordnung schaffen, 459p.

4. Sorensen, "Taking path dependency seriously", 17-38; Amin, “An institutional perspective", 365-378; Keating, Loughlin, and Deschouwer, Culture, 224p.

5. Stöhr and Tödtling, "Spatial equity”, 33-53; Thwaites, "Technological change”, 445461.

6. Cappelo and Nijkamp, "Introduction”, 1-16; Barca, McCann and Rodriguez-Pose, "The case for", 134-152.

7. Porter, The competitive advantage, 855p.; Morgan, "The learning region", 491-503;

Cooke, Uranga and Etxebarria, "Regional innovation systems", 475-491.

8. Martin and Sunley, "Deconstructing cluster evolution”, 1299-1318.

9. Markusen, "Fuzzy concepts", 701.

10. Boschma, "Competitiveness of regions", 1001-1014.

11. Dawley et. al., "Continuity and evolution”, 154-172; Talandier, Jousseaume and Nicot, "Two centuries", 67-87.

12. Popp and Wilson, "Life cycles, 2990.

13. Gadamer, Wahrheit und Methode, 486p.

14. Pollard, "Regional and inter-regional", 57-92; Kiesewetter, Industrielle Revolution, $307 \mathrm{p}$.

15. Doering-Manteuffel, “Kontouren von Ordnung”, 41-64.

16. Pike, Rodriguez-Pose and Tomaney, "What kind of”, 1253-1269.

17. Couperus, Van der Grift and Lagendijk, "Experimental spaces”, 475-479. 


\section{Bibliography}

Amin, Ash. "An institutional perspective on regional economic development." International journal of urban and regional research 23, no 2, (1999): 365-378. DOI: 10.1111/14682427.00201.

Barca, Fabrizio, Philip McCann, and Andres Rodríguez-Pose. "The Case for Regional Development Intervention: Place-Based versus Place-Neutral Approaches.” Journal of regional Science 52, no. 1 (2012): 134-152. DOI: 10.1111/j.1467-9787.2011.00756.x

Boschma, Ron. "Competitiveness of regions from an evolutionary perspective." Regional studies 38, no.9 (2004): 1001-1014. doi.org/10.1080/0034340042000292601

Cappelo, Roberta, and Peter Nijkamp. "Introduction: regional growth and development theories in the twenty-first century - recent theoretical advances and future challenges". In Handbook of regional growth and development theories, edited by idem, 1-16. Cheltanham and Northhampton: Edward Elgar, 2009.

Cooke, Phillip, Mikel Gomez Uranga, and Goio Etxebarria. "Regional innovation systems: Institutional and organisational dimensions. Research Policy 26, no. 4-5 (1997): 475491.

Couperus, Stefan., Liesbeth van der Grift, and Vincent Lagendijk. "Experimental Spaces: A Decentred Approach to Planning in High Modernity. Introduction." Journal of Modern European History 13, no. 4 (2015): 475-479.

Dawley, Stuart, Neill Marshall, Andy Pike, Jane Pollard, and John Tomaney. "Continuity and Evolution in an Old Industrial Region: The Labour Market Dynamics of the Rise and Fall of Northern Rock." Regional Studies 48, no. 1 (2012): 154-172. doi.org/10.1080/00343404.2012.669473

Doering-Manteuffel, A. (2009). "Kontouren von "Ordnung" in den Zeitschichten des 20. Jahrhunderts." In Die Ordnung der Moderne. Social Engineering im 20. Jahrhundert, edited by Thomas Etzemüller, 41-64. Bielefeld: Transcript, 2012.

Gadamer, H.-G. Wahrheit und Methode: Grundzüge einer philosophischen Hermeneutik Tübingen: J.C.B. Mohr, 1960.

Hudson, Ray. Wrecking a region. State policies, party politics and regional change in North East England. London: Pion Limited, 1989.

Keating, Michael, John Loughlin, and Kris Deschouwer. Culture, Institutions and economic development: a study of eight European regions. Cheltanham and Northhampton: Edward Elgar, 2003.

Kiesewetter, Hubert. Industrielle Revolution in Deutschland. Regionen als Wachstumsmotoren. Stuttgart: Franz Steiner Verlag, 2004.

Leendertz, Ariane. Ordnung Schaffen. Deutsche Raumplanung im 20. Jahrhundert. Göttingen: Wallstein Verlag, 2008.

Markusen, Ann. (2003). "Fuzzy concepts, scanty evidence, policy distance: the case for rigour and policy relevance in critical regional studies." Regional studies 37, no. 6-7 (2003): 701-717. doi.org/10.1080/0034340032000108796 
Martin, Ron, and Peter Sunley, "Deconstructing clusters: chaotic concept or policy panacea?" Journal of economic geography 3, no. 1 (2003): 5-35. doi.org/10.1093/jeg/3.1.5

Martin, Ron, and Peter Sunley. "Conceptualizing cluster evolution: beyond the life cycle model?" Regional studies 45, no. 10 (2011): 1299-1318. doi.org/10.1080/00343404.2011.622263

Morgan, Kevin. "The learning region: institutions, innovation, and regional renewal." Regional studies 31, no. 5 (1997): 491-503. doi.org/10.1080/00343409750132289

Pike, Andy, Andres Rodriguez-Pose, and John Tomaney. "What kind of local and regional development and for whom?" Regional Studies 41, no. 9 (2007): 1253-1269. doi.org/10.1080/00343400701543355

Pollard, Sidney. "Regional and inter-regional economic development in Europe in the eighteenth and nineteenth centuries." In Debates and controversies in economic history. Proceedings eleventh international economic history congress, edited by Paola Subacchi, 57-92. Milan: Universita Bocconi, 1994.

Popp, Andrew, and Wilson, John. "Life cycles, contingency, and agency: growth, development, and change in English industrial districts and clusters". Environment and Planning A 39, no. 12 (207): 2975-2992.

Porter, Michael. The competitive advantage of nations. New York: Free Press, 1990.

Sorensen, Andre. "Taking path dependency seriously: an historical institutionalist research agenda in planning history". Planning perspectives 30 no. 1 (2015): 17-38. doi.org/10.1080/02665433.2013.874299

Stöhr, Walter, and Franz Tödtling. Spatial equity - some antitheses to current regional development doctrine. Papers in regional science 38 (1977): 33-53.

Talandier, Magali, Valerie Jousseaume, and Bernard-Henri Nicot. "Two centuries of economic territorial dynamics: the case of France." Regional Studies, Regional Science 3, no.1 (2016): 67-87. doi.org/10.1080/21681376.2015.1090887

Thwaites, A. "Technological change, mobile plants and regional development. Regional Studies 12, no. 4 (1978): 445-461. doi.org/10.1080/09595237800185391 